\title{
Identifikasi Struktur Bawah Permukaan di Daerah Pariwisata Ai Sipatn Lotup Kabupaten Sanggau Menggunakan Metode Geolistrik Resistivitas
}

\author{
M. Riyan Septiansyah*, Muliadi, Zulfian
}

\author{
aProgram Studi Geofisika FMIPA Universitas Tanjungpura, Jl. Prof. Dr. Hadari Nawawi, Pontianak \\ *Email : riyanseptiansyah123@gmail.com \\ (Diterima 19 November 2020; Disetujui 11 Desember 2020; Dipublikasikan 15 Desember 2020)
}

\begin{abstract}
Abstrak
Penelitian ini telah berhasil mengidentifikasi struktur bawah permukaan di daerah pariwisata Ai Sipatn Lotup Desa Sape Kecamatan Jangkang Kabupaten Sanggau dengan menggunakan metode geolistrik resistivitas konfigurasi Wenner-Schlumberger. Pengambilan data dilakukan pada empat lintasan dengan panjang lintasan 1, lintasan 2, dan lintasan 4 adalah 117 m sedangkan lintasan 3 sepanjang $141 \mathrm{~m}$, dengan spasi elektroda terkecil sebesar $3 \mathrm{~m}$. Hasil penampang resistivitas 2D dari empat lintasan menunjukkan nilai resistivitas pada lintasan 1 adalah 15,1 $\Omega \mathrm{m}-15379 \Omega \mathrm{m}$, lintasan 2 adalah 15,25 $\Omega \mathrm{m}-4293 \Omega \mathrm{m}$, lintasan 3 adalah 2,35 $\Omega \mathrm{m}-1748 \Omega \mathrm{m}$, dan lintasan 4 adalah 1,15 $\Omega \mathrm{m}-5277 \Omega \mathrm{m}$. Struktur bawah permukaan di daerah penelitian berdasarkan nilai resistivitas penampang 2D diidentifikasi tanah aluvial, pasir lempungan, batupasir, batu kuarsit, dan batu sabak.
\end{abstract}

Kata Kunci : geolistrik resistivitas, Wenner-Schlumberger, Ai Sipatn Lotup

\section{Latar Belakang}

Kabupaten Sanggau adalah salah satu kabupaten di provinsi Kalimantan Barat. Kabu paten Sanggau terdapat wisata sumber air panas yang bernama Ai Sipatn Lotup yang terletak di Desa Sape, Kecamatan Jangkang. Sumber air panas ini cukup unik karena secara geologis pulau Kalimantan tidak mempunyai gunung berapi sehingga sumber air panas tersebut berasal dari mata air yang dipanaskan oleh panas bumi (geotermal). Sumber air panas ini menjadi salah satu tempat wisata masyarakat setempat, namun fasilitas dan tempat yang tersedia kurang memadai. Informasi tentang struktur bawah permukaan tanah di sekitar tempat wisata $A i$ Sipatn Lotup sangat di perlukan agar lebih memudahkan dalam proses pembangunan infrastruktur di tempat wisata [1].

Perencanaan pembangunan yang cukup baik sangat diperlukan untuk mencegah timbulnya kerusakan bangunan yang kemudian akan menyebabkan penurunan pada bangunan. Suatu bangunan yang dibangun tanpa memperhatikan struktur tanah dan tata lingkungan maka akan memiliki resiko yang lebih besar terhadap kerusakan akibat dari penurunan tanah. Secara prinsip, pondasi harus sampai mencapai tanah keras dan apabila tidak ditemukan tanah keras harus dilakukan pemadatan atau perbaikan tanah [2].

Dalam ilmu sains, cara yang dapat dilakukan untuk mengetahui struktur bawah permukaan adalah dengan memanfaatkan ilmu geofisika. Salah satu metode geofisika yang digunakan adalah menggunakan metode geolistrik. Metode geolistrik sangat baik untuk mengetahui kondisi atau struktur geologi bawah permukaan berdasarkan variasi resistivitas batuannya [3]. Kelebihan dari metode ini adalah tidak merusak lingkungan, biaya relatif murah dan mampu mendeteksi lapisan tanah hingga beberapa meter di bawah permukaan tanah, serta bersifat non destruktif dan bersifat eksplorasi dangkal [4].

Berdasarkan penelitian Syamsurizal et al. (2013), metode geolistrik digunakan untuk identifikasi litologi batuan sebagai studi awal kegiatan pembangunan gedung di Bunderan Purwosari, Surakarta, Jawa Tengah [5]. Penelitian yang sama tentang geolistrik juga pernah dilakukan oleh Sari (2015) untuk interpretasi lapisan bawah permukaan di sekitar manifestasi panas bumi Parangwedan Kabupaten Bantul Yogyakarta [6], dan juga pernah dilakukan oleh Tama (2015) untuk mengetahui struktur bawah permukaan tanah di Kota Lama Semarang [7].

Dalam penelitian ini telah dilakukan identifikasi struktur bawah permukaan di daerah pariwisata Ai Sipatn Lotup Kabupaten Sanggau menggunakan metode geolistrik resistivitas. Penelitian ini di harapkan dapat membantu masyarakat dan pemerintah setempat untuk mempermudah dalam proses pengembangan tempat wisata sumber air panas Ai Sipatn Lotup. 


\section{Metodologi}

\subsection{Metode Geolistrik Resistivitas}

Metode geolistrik adalah suatu teknik investigasi dari permukaan tanah untuk mengetahui lapisan-lapisan batuan atau material berdasarkan pada prinsip bahwa lapisan batuan atau masing-masing material mempunyai nilai resistivitas atau hambatan jenis yang berbedabeda. Survei geolistrik ini bertujuan untuk menentukan distribusi dari nilai resistivitas pada pengukuran yang dilakukan di permukaan tanah.

Resistivitas suatu bahan dapat dituliskan dengan persamaan 1 sebagai berikut:

$$
\rho=\frac{V}{I} \frac{A}{L}
$$

dengan, $\rho=$ nilai resistivitas benda $(\Omega \mathrm{m})$

$$
\begin{aligned}
V & =\operatorname{tegangan} \text { yang } \operatorname{diukur}(\mathrm{V}) \\
I & =\operatorname{arus} \text { yang diukur }(\mathrm{A}) \\
L & =\text { panjang suatu benda }(\mathrm{m}) \\
A & =\text { luas penampang }\left(\mathrm{m}^{2}\right) .
\end{aligned}
$$

Pengambilan data geolistrik menggunakan konfigurasi Wenner-Schlumberger. Susunan elektroda konfigurasi Wenner-Schlumberger terlihat pada Gambar 1. Susunan empat buah elektroda yang terdiri dari dua elektroda penginjeksi arus $\left(\mathrm{C}_{1}\right.$ dan $\left.\mathrm{C}_{2}\right)$ dan dua elektroda pengukur tegangan $\left(\mathrm{P}_{1}\right.$ dan $\left.\mathrm{P}_{2}\right)$. Secara umum, kedalaman pengujian dapat diperbesar dengan menambah jarak antara dua elektroda arus.

Nilai tegangan antara titik $\mathrm{P}_{1}$ dan $\mathrm{P}_{2}$ adalah:

$$
\begin{aligned}
\Delta V & =\left[\frac{I \rho}{2 \pi}\left(\frac{1}{r_{1}}-\frac{1}{r_{2}}\right)\right]-\left[\frac{I \rho}{2 \pi}\left(\frac{1}{r_{3}}-\frac{1}{r_{4}}\right)\right] \\
& =\frac{I \rho}{2 \pi}\left[\left(\frac{1}{r_{1}}-\frac{1}{r_{2}}\right)-\left(\frac{1}{r_{3}}-\frac{1}{r_{4}}\right)\right]
\end{aligned}
$$

dimana $\Delta V$ adalah tegangan antara $\mathrm{P}_{1}$ dan $\mathrm{P}_{2}(\mathrm{~V})$, $I$ adalah kuat arus yang terukur oleh $\mathrm{C}_{1}$ dan $\mathrm{C}_{2}$ (A), $\rho$ adalah resistivitas bahan $(\Omega \mathrm{m}), r_{1}$ adalah jarak antara $\mathrm{C}_{1}$ dan $\mathrm{P}_{1}(\mathrm{~m}), r_{2}$ adalah jarak antara $\mathrm{C}_{2}$ dan $\mathrm{P}_{1}(\mathrm{~m}), r_{3}$ adalah jarak antara $\mathrm{C}_{1}$ dan $\mathrm{P}_{2}(\mathrm{~m})$ dan $r_{4}$ adalah jarak antara $\mathrm{C}_{2}$ dan $\mathrm{P}_{2}(\mathrm{~m})$ [8].

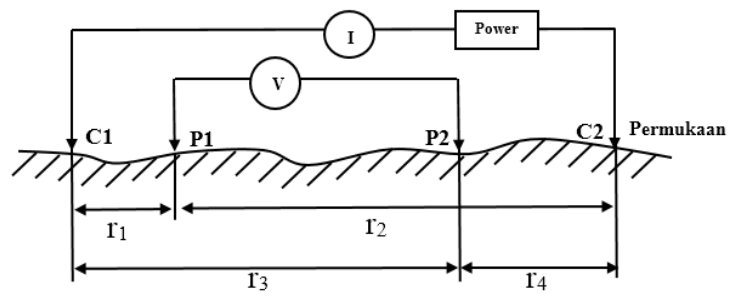

Gambar 1. Susunan elektroda arus dan tegangan [8]

\subsection{Faktor Geometri}

Konfigurasi Wenner-Schlumberger adalah konfigurasi dengan sistem aturan spasi yang tetap dengan catatan faktor $\mathrm{n}$ untuk konfigurasi Wenner-Schlumberger adalah perbandingan jarak antara elektroda $\mathrm{C}_{1}-\mathrm{C}_{2}$ adalah 2na+a. Proses penentuan resistivitas menggunakan empat buah elektroda yang diletakkan dalam sebuah garis lurus, yang ditunjukkan pada Gambar 2 [3].

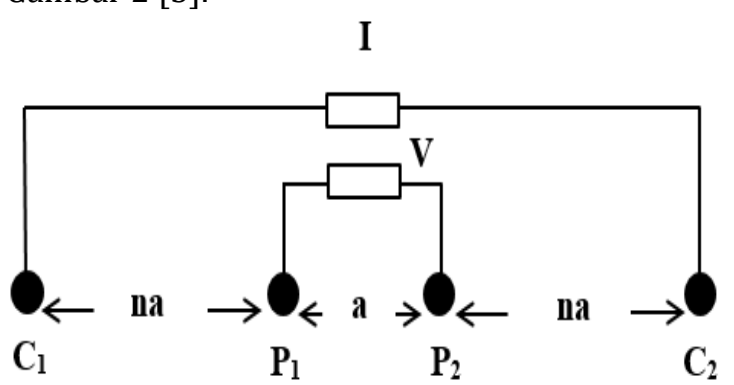

Gambar 2. Pengaturan elektroda konfigurasi Wenner-Schlumberger [3]

Faktor geometri $(K)$ pada metode geolistrik konfigurasi Wenner-Schlumberger adalah [9]:

$$
K=\pi n(n+1) a
$$

dengan, $K=$ faktor geometri $(\mathrm{m})$

$n=$ jarak antar elektroda potensial

$a=$ jarak elektroda terkecil (m).

\subsection{Resistivitas Batuan}

Nilai resistivitas suatu material dimanfaatkan dalam metode geolistrik untuk menyelidiki struktur bawah permukaan. Resistivitas dari batuan maupun mineral memper-lihatkan nilai yang bervariasi. Variasi nilai resistivitas batuan ditunjukkan pada Tabel 1.

\subsection{Akuisisi Data}

Penelitian ini dilakukan di sumber air panas Ai Sipatn Lotup Kampung Peruntan, Desa Sape, Kecamatan Jangkang, Kabupaten Sanggau yang ditunjukan oleh Gambar 3. Koordinat penelitian terletak pada $00,396922^{\circ}-00,397498^{\circ} \mathrm{LU}$ dan $110,821402^{\circ}-110,820778^{\circ} \mathrm{BT}$.

Pengambilan data geolistrik resistivitas pada penelitian ini menggunakan konfigurasi Wenner-Schlumberger untuk melihat sebaran resistivitas batuan. Berdasarkan Gambar 3, pengukuran dilakukan pada satu lokasi yang terdiri dari empat lintasan dengan panjang lintasan 1, lintasan 2 dan lintasan 4 adalah 117 meter sedangkan panjang lintasan 3 adalah 141 meter. Luas area yang diteliti sebesar $260 \mathrm{~m} \mathrm{x}$ $160 \mathrm{~m}$. 


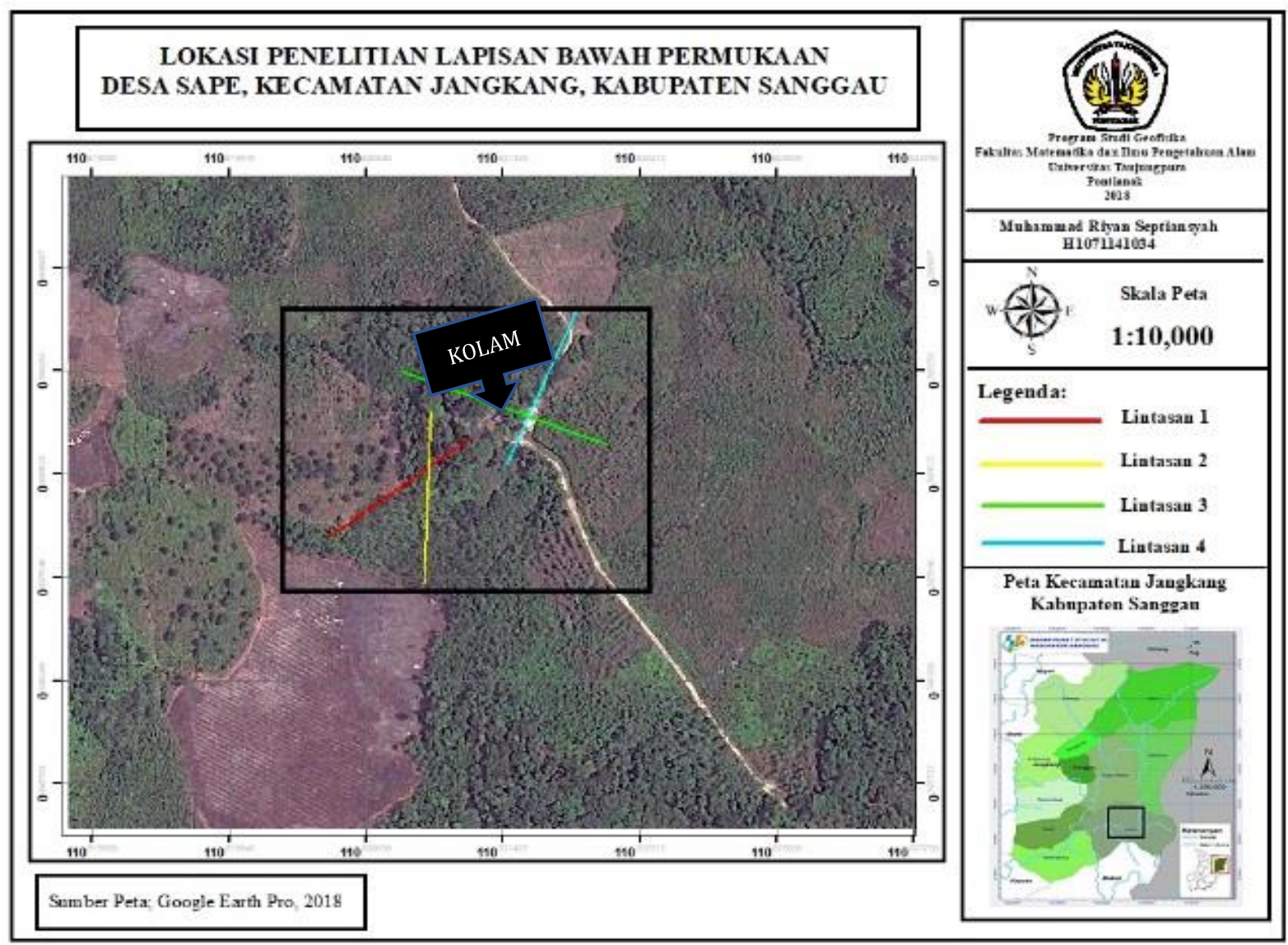

Gambar 3. Lokasi penelitian [10]

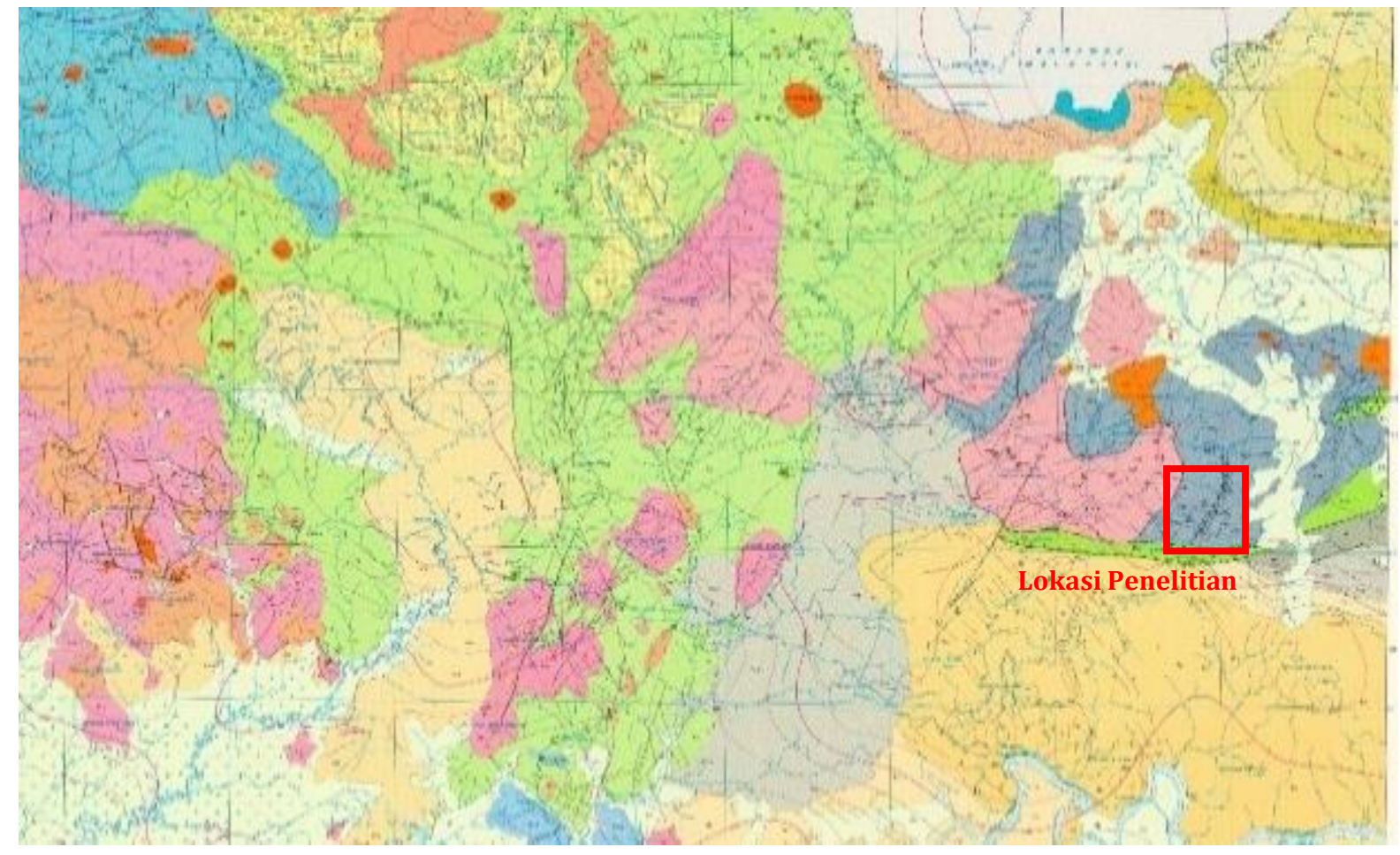

Gambar 4. Peta geologi lembar Sanggau, Kalimantan Barat [11] 
Lintasan 1 dan lintasan 2 saling memotong di bukit yang ada di sekitar tempat wisata $A i$ Sipatn Lotup selain itu lintasan 3 dan lintasan 4 juga saling berpotongan (Gambar 3). Jarak setiap elektroda (spasi) terkecil masing-masing lintasan sebesar 3 meter. Lintasan 1 dan lintasan 2, lintasan 4 menggunakan 40 elektroda, sedangkan lintasan 3 menggunakan 48 elektroda. Lintasan penelitian yang digunakan membentang mengelilingi tempat wisata air panas.

Tabel 1. Resistivitas batuan

\begin{tabular}{|c|c|c|}
\hline No & Batuan & Resistivitas $(\Omega \mathrm{m})$ \\
\hline 1 & $\begin{array}{l}\text { Top soil (tanah } \\
\text { penutup) }\end{array}$ & $250-1700$ \\
\hline 2 & $\begin{array}{l}\text { Consolidated shales } \\
\text { (serpihan padat) }\end{array}$ & $20-2 \times 10^{3}$ \\
\hline 3 & Argillites & $10-8 \times 10^{2}$ \\
\hline 4 & Lanau (Silt) & $10-200$ \\
\hline 5 & Batu pasir (sandstone) & $1-6,4 \times 10^{8}$ \\
\hline 6 & $\begin{array}{l}\text { Batu gamping } \\
\text { (limestone) }\end{array}$ & $50-10^{7}$ \\
\hline 7 & Dolomite & $\begin{array}{l}3.5 \times 10^{2}-5 \times \\
10^{3}\end{array}$ \\
\hline 8 & $\begin{array}{l}\text { Unconsolidated wet } \\
\text { clay (lempung basah } \\
\text { tidak padat) }\end{array}$ & 20 \\
\hline 9 & Lempung (Clay) & $1-100$ \\
\hline 10 & $\begin{array}{l}\text { *Lempung pasiran / } \\
\text { pasir lempungan } \\
\text { (Sandy clay / Clayey } \\
\text { sand) }\end{array}$ & $10,18-19,87$ \\
\hline 11 & Andesit & $\begin{array}{l}1,70 \times 10^{2}- \\
4,5 \times 10^{4}\end{array}$ \\
\hline 12 & Kuarsit & $\begin{array}{l}3 \times 10^{2}-3 \times \\
10^{5}\end{array}$ \\
\hline 13 & Basalt & $10-1,3 \times 10^{7}$ \\
\hline 14 & Tuff & $\begin{array}{l}2 \times 10^{3} \\
\text { (basah) }-10^{5} \\
\text { (kering) }\end{array}$ \\
\hline 15 & Alluvium dan pasir & $10-800$ \\
\hline 16 & Oil sands & $4-800$ \\
\hline 17 & Pasir (Sand) & $1-10^{3}$ \\
\hline 18 & Sand and gravel & $30-215$ \\
\hline 19 & Granit & $3 \times 10^{2}-10^{6}$ \\
\hline 20 & Diorit & $10^{4}-10^{5}$ \\
\hline 21 & Batu sabak & $\begin{array}{l}6 \times 10^{2}-4 \times \\
10^{7}\end{array}$ \\
\hline
\end{tabular}

Sumber: [8]; *[15]

\subsection{Akuisisi Data}

Penelitian ini dilakukan di sumber air panas Ai Sipatn Lotup Kampung Peruntan, Desa Sape, Kecamatan Jangkang, Kabupaten Sanggau yang ditunjukkan Gambar 4. Koordinat peneli-tian terletak pada $00,396922^{\circ}-00,397498^{\circ} \mathrm{LU}$ dan $110,821402^{\circ}-110,820778^{\circ} \mathrm{BT}$.

Pengambilan data geolistrik resistivitas pada penelitian ini menggunakan konfigurasi
Wenner-Schlumberger untuk melihat sebaran resistivitas batuan. Berdasarkan Gambar 3, pengukuran dilakukan pada satu lokasi yang terdiri dari empat lintasan dengan panjang lintasan 1, lintasan 2 dan lintasan 4 adalah 117 meter sedangkan panjang lintasan 3 adalah 141 meter. Luas area yang diteliti $260 \mathrm{~m}$ x $160 \mathrm{~m}$.

Lintasan 1 dan lintasan 2 saling memotong di bukit yang ada di sekitar tempat wisata $A i$ Sipatn Lotup selain itu lintasan 3 dan lintasan 4 juga saling berpotongan (Gambar 3). Jarak setiap elektroda (spasi) terkecil masing-masing lintasan sebesar 3 meter. Lintasan 1 dan lintasan 2, lintasan 4 menggunakan 40 elektroda, sedangkan lintasan 3 menggunakan 48 elektroda. Lintasan penelitian yang digunakan membentang mengelilingi tempat wisata air panas.

\subsection{Geologi Tempat Penelitian}

Keadaan geologi Sanggau menggambarkan kelompok perbukitan dan pegunungan yang terpisah-pisah serta beberapa dataran rendah. Kondisi geologi daerah Ai Sipatn Lotup, Desa Sape, Kecamatan Jangkang, Kabupaten Sanggau terletak pada kelompok Balai Sebut yang terlihat pada kotak merah di Gambar 4.

Kelompok Balai Sebut terdiri atas batu sabak, batulumpur, batulanau, dan batupasir, setempat serpih, kuarsit, filit, sekis, marmer dan rijang. Kelompok Balai Sebut diterobos oleh Kompleks Embuoi dan memiliki kontak sesar dengan Kelompok Selangkai dan Formasi Payak. Kelompok Balai Sebut berumur permokarbon dan menunjukkan ciri lingkungan pengendapan laut dalam - laut dangkal dan darat [10].

\section{Hasil dan Pembahasan}

\subsection{Analisis pada Lintasan 1}

Lintasan 1 membentang ke arah Barat Daya. Posisi patok awal di lintasan 1 berada pada koordinat $00,397062^{\circ} \mathrm{LU}$ dan $110,821170^{\circ} \mathrm{BT}$ dengan data lapangan menuju ke arah Barat Daya sebesar $231,8^{\circ}$. Sedangkan posisi patok terakhir di lintasan 1 berada pada koordinat $00,396452^{\circ}$ LU dan $110,820324^{\circ}$ BT dengan data lapangan mengarah ke arah Timur Laut sebesar 63,8 . Lintasan 1 berada di daerah bukit sekitar kolam air panas. Hal ini bertujuan untuk memperoleh panampang resistivitas 2D di daerah bukit yang berada di dekat kolam air panas.

Gambar 5 merupakan penampang resisitivitas 2D pada lintasan 1. Dari hasil penampang model tersebut diperoleh kedalaman pengukuran mencapai 23,6 meter dengan iterasi sebanyak 15 kali dan RMS-error sebesar 20,5\%. Hasil interpretasi Gambar 5 didapatkan rentang nilai resistivitas yang berbeda-beda, yaitu dari resistivitas sebesar 15,1 $\Omega \mathrm{m}-15379 \Omega \mathrm{m}$. Lintasan ini memiliki panjang bentangan sebesar 117 meter. 


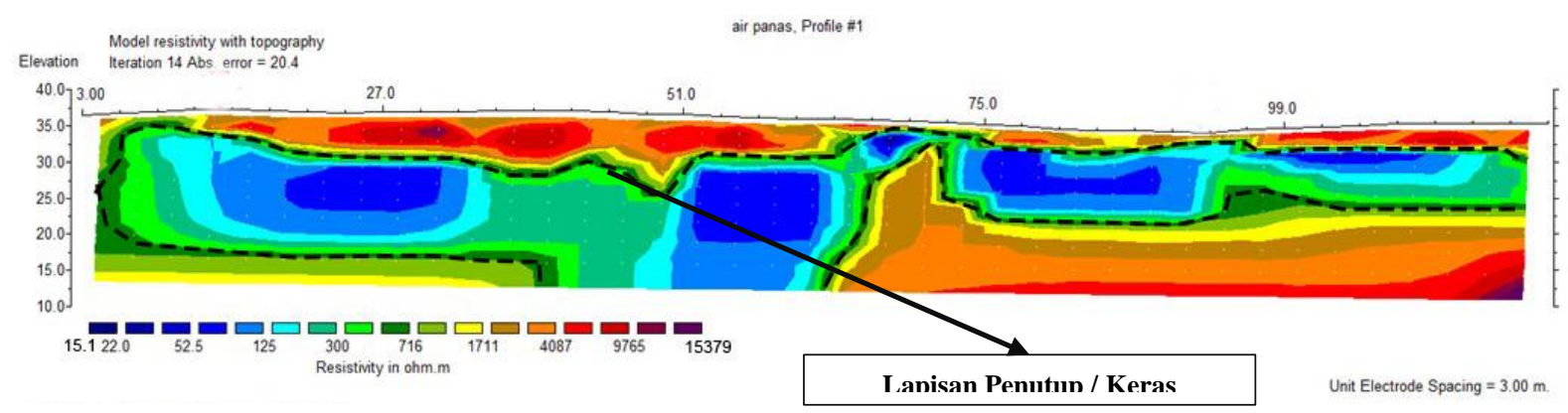

Gambar 5. Penampang resistivitas $2 \mathrm{D}$ pada lintasan 1

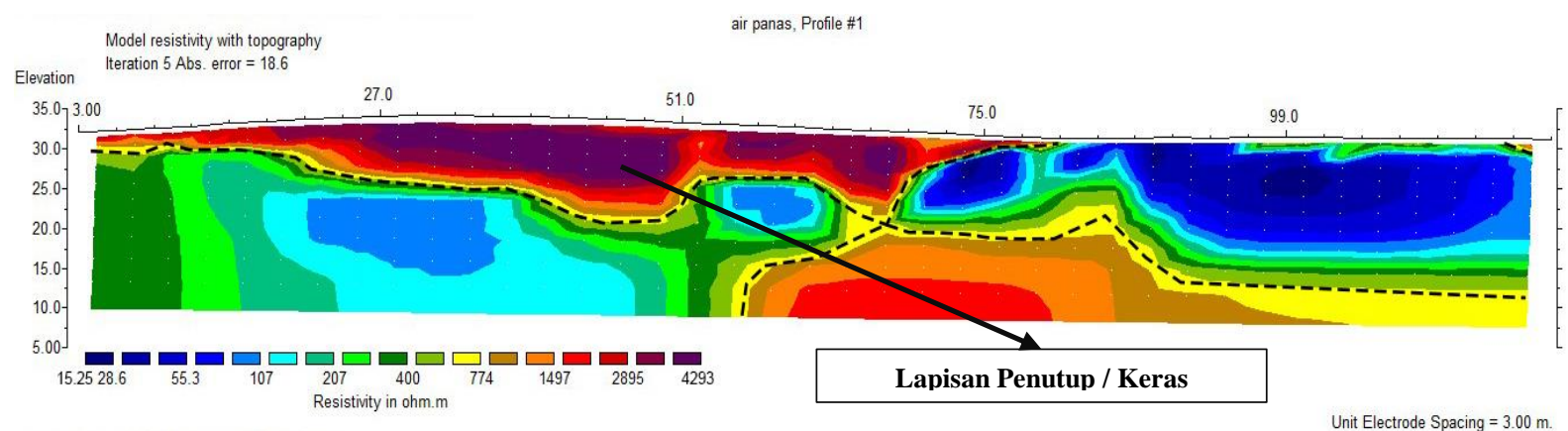

Gambar 6. Penampang resistivitas 2D pada lintasan 2

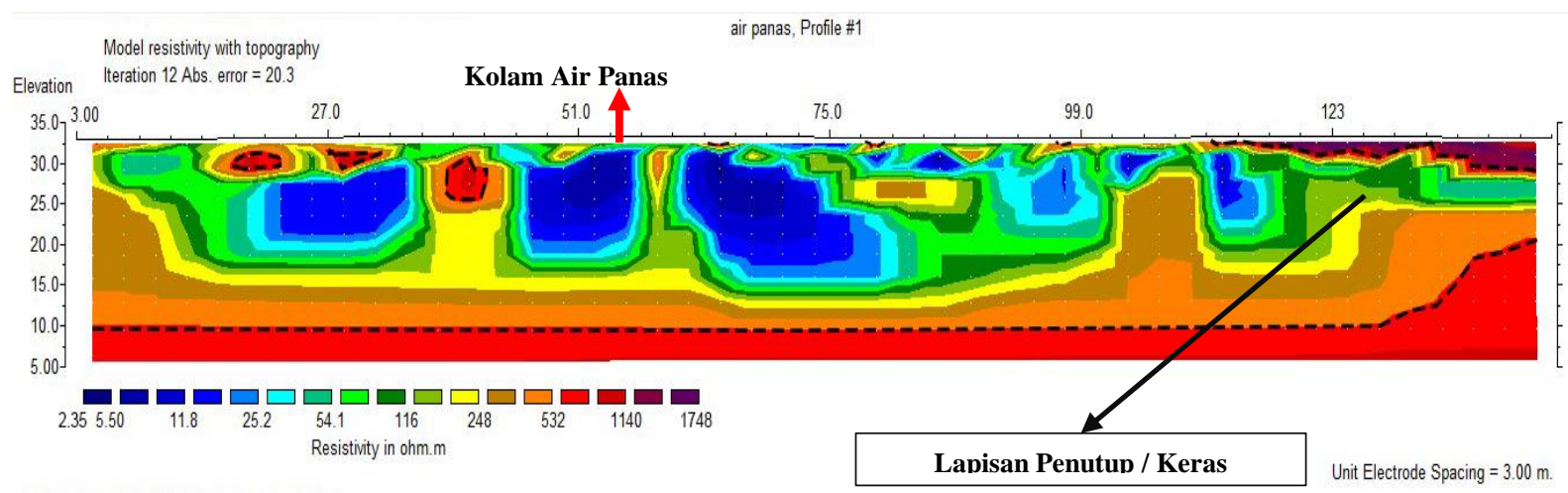

Gambar 7. Penampang resistivitas 2D pada lintasan 3

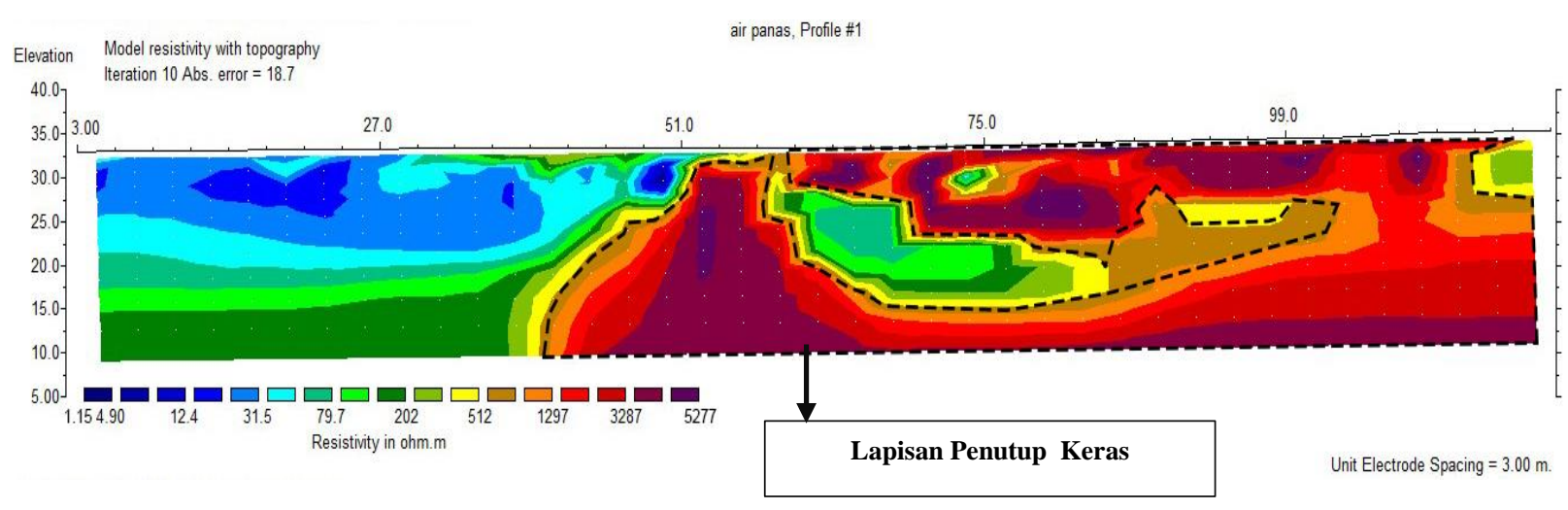

Gambar 8. Penampang resistivitas 2D pada lintasan 4 
Jenis batuan pertama dengan rentang nilai resitivitas berkisar 15,1 $\Omega \mathrm{m}-87,9 \Omega \mathrm{m}$ dengan kedalaman yang bervariasi dari 2 - 15 meter. Jenis batuan ini diinterpretasi sebagai pasir lempungan (clayey sand) dan tanah aluvial (alluvial soil). Jenis batuan kedua dengan rentang nilai resistivitas berkisar $88 \Omega \mathrm{m}-606 \Omega \mathrm{m}$ dapat diinterpretasikan sebagai batupasir (sandstone) dengan kedalaman sekitar 0,75 - 23,6 meter. Jenis batuan ketiga dengan rentang nilai resistivitas berkisar 606,8 $\Omega \mathrm{m}-15379 \Omega \mathrm{m}$ dapat diinterpretasikan sebagai batu kuarsit (quarts stone) dan batu sabak (slate stone) dengan kedalaman sekitar 0,75-23,6 meter.

\subsection{Analisis pada Lintasan 2}

Lintasan 2 membentang ke arah Selatan. Posisi patok awal di lintasan 2 berada pada koordinat $00,397229^{\circ} \mathrm{LU}$ dan $110,820954^{\circ} \mathrm{BT}$ dengan data lapangan menuju ke arah Selatan sebesar $190,9^{\circ}$. Sedangkan posisi patok terakhir di lintasan 2 berada pada koordinat $00,396203^{\circ}$ LU dan $110,820883^{\circ}$ BT dengan data lapangan mengarah ke arah Utara sebesar 7,40. Lintasan 2 adalah lintasan yang berada di daerah bukit sekitar kolam air panas dan memotong lintasan 1. Lintasan ini memiliki panjang bentangan sebesar 117 meter.

Gambar 6 merupakan hasil inversi penampang resistivitas 2D pada lintasan 2. Dari hasil penampang model tersebut diperoleh kedalaman pengukuran mencapai 23,6 meter dengan iterasi sebanyak 5 kali dan $R M S$-error sebesar 18,6 \%. Hasil interpretasi Gambar 6 didapatkan rentang nilai resistivitas yang berbeda-beda, yaitu dari 15,25 $\Omega$ m sampai 4293 $\Omega \mathrm{m}$.

Jenis batuan pertama memiliki rentang nilai resitivitas berkisar 15,25 $\Omega \mathrm{m}-81,15 \Omega \mathrm{m}$ dengan kedalaman yang bervariasi dari 0,75 - 14 meter. Jenis batuan ini diinterpretasi sebagai pasir lempungan dan tanah aluvial. Jenis batuan kedua dengan rentang nilai resistivitas berkisar 81,16 $\Omega \mathrm{m}-610,3 \Omega \mathrm{m}$ dapat diinterpretasikan sebagai batupasir dengan kedalaman sekitar 0,75-23,6 meter. Jenis batuan ketiga dengan rentang nilai resistivitas berkisar $610,4 \Omega \mathrm{m}-4293 \Omega \mathrm{m}$ dapat diinterpretasikan sebagai batu kuarsit dan batu sabak dengan kedalaman sekitar 0,75 - 23,6 meter.

\subsection{Analisis pada Lintasan 3}

Lintasan 3 membentang ke arah Tenggara. Posisi patok awal di lintasan 3 berada pada koordinat $00,397498^{\circ} \mathrm{LU}$ dan $110,820778^{\circ} \mathrm{BT}$ dengan data lapangan menuju ke arah Tenggara sebesar $113,3^{\circ}$. Sedangkan posisi patok terakhir di lintasan 3 berada pada koordinat $00,397049^{\circ}$ LU dan $110,821985^{\circ}$ BT dengan data lapangan mengarah ke arah Barat sebesar 290,9. Lintasan 3 bertepatan di kolam inti air panas. Hal ini dimaksudkan agar mendapatkan nilai resistivitas batuan yang beragam karena memotong kolam air panas yang ada di daerah penelitian sehingga mendapatkan hasil nilai resistivitas batuan yang signifikan. Lintasan ini memiliki panjang bentangan 141 meter.

Gambar 7 merupakan hasil inversi penampang resistivitas 2D pada lintasan 3. Dari hasil penampang model tersebut diperoleh kedalaman pengukuran mencapai 27,4 meter dengan iterasi sebanyak 12 kali dan RMS-error sebesar 20,3 \%. Hasil interpretasi Gambar 7 didapatkan rentang nilai resistivitas yang berbeda-beda, yaitu sebesar $2,35 \Omega \mathrm{m}$ - $1748 \Omega \mathrm{m}$.

Jenis batuan pertama dengan rentang nilai resitivitas berkisar 2,35 $\Omega \mathrm{m}-85,05 \Omega \mathrm{m}$ dengan kedalaman yang bervariasi dari 0,75 - 18 meter. Jenis batuan ini diinterpretasi sebagai pasir lempungan dan tanah aluvial. Jenis batuan kedua dengan rentang nilai resistivitas berkisar 85,1 $\Omega \mathrm{m}-607,9 \Omega \mathrm{m}$ dapat diinterpretasikan sebagai batupasir dengan kedalaman sekitar 0,75 - 27 meter. Jenis batuan ketiga dengan rentang nilai resistivitas berkisar $608 \Omega \mathrm{m}$ - $1748 \Omega \mathrm{m}$ dapat diinterpretasikan sebagai kuarsit dan batu sabak dengan kedalaman sekitar 0,75 - 27,4 meter.

\subsection{Analisis pada Lintasan 4}

Lintasan 4 membentang ke arah Timur Laut. Posisi patok awal di lintasan 4 berada pada koordinat $00,396922^{\circ} \mathrm{LU}$ dan $110,821402^{\circ} \mathrm{BT}$ dengan data lapangan menuju ke arah Timur Laut sebesar $34,8^{\circ}$. Sedangkan posisi patok terakhir di lintasan 4 berada pada koordinat $00,397876^{\circ} \mathrm{LU}$ dan $110,821854^{\circ} \mathrm{BT}$ dengan data lapangan mengarah ke arah Selatan sebesar $191,5^{\circ}$. Lintasan 4 memotong lintasan 3, hal ini dimaksudkan agar mendapatkan nilai resistivitas batuan yang beragam karena memotong wilayah di dekat kolam inti air panas yang ada di daerah penelitian sehingga mendapatkan hasil nilai resistivitas batuan yang signifikan. Lintasan ini juga berada pada bukit yang berada disekitar sumber kolam air panas. Lintasan 4 memiliki panjang bentangan 117 meter.

Gambar 8 merupakan hasil inversi penampang resistivitas 2D pada lintasan 4 . Dari hasil penampang model tersebut diperoleh kedalaman pengukuran mencapai 23,6 meter dengan iterasi sebanyak 10 kali dan RMS-error sebesar 18,7 \%. Hasil interpretasi Gambar 8 didapatkan rentang nilai resistivitas yang berbeda-beda, yaitu dari resistivitas yang rendah sebesar $1,15 \Omega \mathrm{m}$ sampai resistivitas yang terbesar mencapai $5277 \Omega \mathrm{m}$.

Jenis batuan pertama memiliki rentang nilai resitivitas berkisar 1,15 $\Omega \mathrm{m}-87,3 \Omega \mathrm{m}$ dengan 
kedalaman yang bervariasi dari 0,75 - 15 meter. Jenis batuan ini diinterpretasi sebagai pasir lempungan dan tanah aluvial. Jenis batuan kedua dengan rentang nilai resistivitas berkisar 87,4 $\Omega \mathrm{m}-610 \Omega \mathrm{m}$ dapat diinterpretasikan sebagai batupasir dengan kedalaman sekitar 0,75 - 23,6 meter. Jenis batuan ketiga dengan rentang nilai resistivitas berkisar 610,1 $\Omega \mathrm{m}-5277 \Omega \mathrm{m}$ dapat diinterpretasikan sebagai batu kuarsit dan batu sabak dengan kedalaman sekitar 0,75 - 23,6 meter.

\subsection{Analisis Stuktur Bawah Permukaan Tanah pada Empat Lintasan}

Hasil citra penampang resistivitas 2D menunjukkan bahwa daerah penelitian terdapat beberapa jenis batuan, yaitu batuan pasir lempungan, tanah aluvial, batupasir, batu kuarsit dan batu sabak. Struktur batuan pada keempat lintasan memiliki dua lapisan yaitu lapisan batuan dengan struktur yang padat atau keras dan struktur yang kurang padat.

Gambar 5, Gambar 6, Gambar 7 dan Gambar 8 memperlihatkan bahwa struktur batuan yang padat atau keras ditandai dengan garis hitam putus-putus. Struktur batuan yang padat pada lintasan 1 memiliki rentang nilai resistivitas berkisar 606,8 $\Omega \mathrm{m}-15379 \Omega \mathrm{m}$, lintasan 2 memiliki rentang nilai resistivitas berkisar 610,4 $\Omega \mathrm{m}-4293 \Omega \mathrm{m}$, lintasan 3 memiliki rentang nilai resistivitas berkisar $608 \Omega \mathrm{m}-1748 \Omega \mathrm{m}$ dan lintasan 4 memiliki rentang nilai resistivitas berkisar 610,1 $\Omega \mathrm{m}$ - $5277 \Omega \mathrm{m}$. Berdasarkan Tabel 1, nilai resistivitas batuan yang diprediksi sebagai struktur batuan padat adalah batu kuarsit dan batu sabak. Kedalaman struktur batuan padat dominan di empat lintasan dominan dikedalaman 0 - 9 meter di bawah permukaan bumi. Namun pada lintasan 3 struktur batuan padatnya dominan di bawah permukaan bumi 16 - 27,4 meter.

Struktur batuan yang kurang padat di lintasan 1 memiliki memiliki rentang nilai resistivitas berkisar 15,1 $\Omega \mathrm{m}-606 \Omega \mathrm{m}$, lintasan 2 memiliki rentang nilai resistivitas berkisar 15,1 $\Omega \mathrm{m}-610,3 \Omega \mathrm{m}$, lintasan 3 memiliki rentang nilai resistivitas berkisar 2,35 $\Omega \mathrm{m}-607 \Omega \mathrm{m}$ dan lintasan 4 memiliki rentang nilai resistivitas berkisar 1,15 $\Omega \mathrm{m}-610 \Omega \mathrm{m}$. Berdasarkan Tabel 1, nilai resistivitas batuan yang diprediksi sebagai struktur batuan kurang padat adalah tanah aluvial, pasir lempungan dan batupasir. Kedalaman struktur batuan kurang padat dominan berada pada 0 - 12 meter dengan diselingi oleh batuan yang padat. Struktur batuan kurang padat dominan di setiap lintasan.

Batu kuarsit dan batu sabak merupakan zona lapisan padat dari keempat lintasan, lapisan batuan ini memiliki daya dukung yang kuat. Daya dukung yang kuat dari batu kuarsit dan batu sabak dapat digunakan dalam kontruksi sebagai letak pondasi bangunan [12]. Pada lapisan ini dapat dibangun bangunan menggunakan pondasi yang dangkal karena struktur bawah permukaan daerah tersebut berupa batuan padat.

Tanah aluvial, pasir lempungan dan batupasir merupakan lapisan tanah yang diduga sebagai struktur batuan yang kurang padat. Umumnya lapisan tanah yang kurang padat terdiri dari tanah yang sebagian besar terdiri dari butir-butir yang sangat kecil. Pada lapisan tanah yang kurang padat ini apabila terdapat beban kontruksi yang melampaui daya dukung kritis, maka akan terjadi kerusakan pada pondasi bangunan. Meskipun intensitas beban berkurang dari daya dukung kritis, dalam jangka waktu yang lama besarnya penurunan akan meningkat. Pembuatan pondasi pada lapisan ini dapat dilakukan dengan pemadatan atau pemilihan konstruksi pondasi dalam (deep foundation) terlebih dahulu agar bisa mengurangi gaya geser pada tanah yang kurang padat tersebut [14].

Tanah aluvial, pasir lempungan dan batupasir mendominasi pada lintasan 3, sedangkan batu kuarsit dan batu sabak banyak terdapat di lapisan bawah permukaan tanah. Hal ini karena lokasi lintasan 3 berada di sekitar kolam sumber air panas yang permukaan tanahnya terdapat tanah aluvial dan pasir lempungan serta genangan air. Sifat pasir lempungan yang memiliki permeabilitas sedang menyebabkan mudah untuk menyimpan dan meloloskan air sehingga nilai resistivitas di sekitar jarak tersebut rendah.

Lintasan 4 memiliki perbedaan keadaan batuan yang sangat signifikan antara lapisan batuan kurang padat dan batuan yang padat. Hal ini dikarenakan pada lintasan 4 dengan jarak 0 54 meter merupakan daerah yang memotong lintasan 3. Lintasan 3 didominasi batuan yang memiliki nilai resistivitas rendah karena berada di pinggiran aliran air sungai serta pada jarak ini struktur lapisan tanahnya kurang padat. Selain itu pada jarak tersebut diduga sebagai batas batuan dari jalur sumber air panas antara batuan kurang padat dan padat yang mengarah langsung ke kolam air panas. Sedangkan pada jarak 51 117 meter berada pada bukit yang didominasi dengan batuan keras sehingga nilai resistivitasnya jauh lebih tinggi serta perbedaan ini juga disebabkan karena perbedaan ketinggian di lintasan tersebut. 


\section{Kesimpulan}

Berdasarkan hasil interpretasi penampang resistivitas 2 dimensi, maka dapat disimpulkan bahwa struktur permukaan bawah tanah dari empat lintasan pengambilan data di daerah pariwisata Ai Sipatn Lotup Desa Sape, Kecamatan Jangkang, Kabupaten Sanggau terdiri dari pasir lempungan, tanah aluvial, batupasir, kuarsit dan batu sabak. Struktur batuan yang padat adalah batuan kuarsit dan batu sabak, sedangkan struktur batuan yang kurang padat adalah pasir lempungan, tanah aluvial dan batupasir. Struktur batuan yang padat dapat dilakukan pembangunan, namun perlu dilakukan juga pemadatan atau pemilihan konstruksi pondasi dalam agar bisa mengurangi gaya geser pada tanah yang kurang padat pada daerah tersebut.

\section{Daftar Pustaka}

[1] Ulfa, M., Azwar, A., and Muhardi, Identifikasi Struktur Bawah Permukaan Area Sumber Air Panas Non-Vulkanik di Kabupaten Sanggau Berdasarkan Citra Satelit ERS-1 Geosat, PRISMA FISIKA, 7(2), pp. 127-133, 2019.

[2] Sulastri, S., Hasyim, and Soemarno, Konsep Pengembangan Ekowisata Malang Selatan Poros Sendang Biru-Gondanglegi, Malang: PM PSLP-PPSUB, 2010.

[3] Hendri, Faryuni, I, D., and Zulfian, Identifikasi Bidang Gelincir dan Tipe Tanah Longsor di Daerah Rawan Longsor Desa Bantai Menggunakan Metode Geolistrik, PRISMA FISIKA, 7(3), pp. 167-174, 2019.

[4] Darsono., Nurlaksito, B. and Legowo, B., Identifikasi Bidang Gelincir Pemicu Benca na Tanah Longsor Dengan Metode Resisti vitas 2 Dimensi Di Desa Pablengan Keca matan Matesih Kabupaten Karanganyar, Jurusan Fisika Fakultas MIPA Universitas Sebelas Maret Surakarta, Indonesian Journal of Applied Physics, 2(1), 57-66, 2012.

[5] Syamsurizal., Cari., and Darsono., Aplikasi Metoda Resistivitas untuk Identif ikasi Litologi Batuan Sebagai Studi Awal Kegiatan Pembangunan Pondasi Gedung, Jurusan Fisika FMIPA Universitas Sebelas Maret Surakarta, Indonesian Journal of Applied Physics, 3(1), pp. 99-106, 2004.

[6] Sari, E.P., Interpretasi Lapisan Batuan Bawah Permukaan di Sekitar Manifestasi Panas Bumi Parangwedang Kabupaten Ba ntul Yogyakarta Berdasarkan Pengukuran Geolistrik dengan Metode Resistivitas, Fakultas Sains dan Teknologi, UIN Sunan Kalijaga, Yogyakarta, 2015.
[7] Tama, K.S., Struktur Bawah Permukaan Tanah di Kota Lama Semarang Mengguna kan Metode Geolistrik Resistivity Konfigu rasi Schlumberger, FMIPA Universitas Negeri Semarang, Semarang, 2015.

[8] Telford, W.M., Geldart, L.P., Sheriiff, R.E. and Keys, D.A., Applied Geophysics, Cambridge University Press., London, 1990.

[9] Sampurno, J., Setiadi, M., and Apriansyah, Idebtifikasi Sebaran Batuan Beku Di Bukit Koci Desa Sempalai Kabupaten Sambas Kalimantan Barat Dengan Menggunakan Metode Geolistrik Resistivitas, Universitas Tanjungpura, POSITRON, Vol. VI, No. 2, 2016.

[10] Google Earth Pro,Tempat Penelitian Desa Sape Kecamatan Jangkang Kabupaten Sanggau, http://www.google-earthpro.id.uptodown.com, (1 Desember 2018).

[11] Supriatna, S., Margono, U., Sutrisno., Pieters, P.E. and Langford, R.P., Peta Geologi Lembar Sanggau, Kalimantan, Pusat Penelitian dan Pengembangan Geol ogi, Bandung, 1993.

[12] Mabrur, M., and Putri, W.N., Analisis Penurunan Pondasi Tiang pada Bangunan Berlantai Banyak di Wilayah Lapisan End apan Aluvium Kota Banda Aceh, Jurusan Teknik Sipil, Politeknik Negeri Medan, Medan, 2019,

[13] Gunawan, G., Oetojo, P.D., Prananda, I.A., and Silvester, F., Pemanfaatan Batu Karang dan Pasir Laut untuk Bidang Jala n Teknologi Jalan Ramah Lingkungan, Pusat Penelitian dan Pengembangan Jalan dan Jembatan, Kementerian Pekerjaan Umum, Bandung, 2011.

[14] Ayu, M.P., Identifikasi Batuan Dasar di Desa Kroyo Karangmalang Kabupaten Sra gen Menggunakan Metode Geolistrik Konf igurasi Dipole-Dipole, FMIPA Univesitas Sebelas Maret, Surakarta, 2009.

[15] Setiono, D., Pudjoharto, H., and Krisna, W., Penyelidikan Zona Akuifer Menggunakan Geolistrik Metode Schlumberger di Sekitar Pantai Utara Kecamatan Kramat, Suradadi dan Warureja Kabupaten Tegal., Jawa Tengah, 2014. 